\title{
Modeling and Analyzing Macro-Economic Variables as Risk Factors: Evidence from Pakistani Stock Exchange
}

\author{
Fauzia Mubarik ${ }^{1}$ \\ Attiya Yasmin Javid ${ }^{2}$
}

\begin{abstract}
This study attempts to investigate seven macroeconomic risk factors' effect on fifty stock returns of Pakistani stock market for the time period of July 1998 to June 2014 respectively. The sensitivity coefficients of macro-economic risk variables are identified as market return, money supply, industrial production, and call money rate, term structure of interest rate, exchange rate and inflation. This study jointly estimates economic risk factors and also risk premium associated with these risk factors by employing extended arbitrage pricing theory (APT) model by applying non-linear seemingly unrelated regression. The innovation of each economic variable is used as risk factor and the study estimates the sensitivities of risk factors and the premium for risk using extended APT model. The results indicate that the money supply risk positively affects stock returns and the industrial production, inflationary shock, exchange rate, call rate and the term structure shocks negatively affect the stock returns respectively. Among all the macro-economic risks, the risk premium for the stock returns is significant for facing market risk, inflation risk and interest rate risk. The results of the study imply that since risk premium is the reward for taking risk while holding stock market assets, if the predictable risk increases, it reduces uncertainty of the stocks. Therefore investors, authorities and policy makers are needed to take into account the economic risk factors while considering the sensitivity of stock returns in making decisions.
\end{abstract}

Keywords: Arbitrage pricing theory, macroeconomic risk factors, risk premium, Non-Linear Seemingly Unrelated Regression (NSUR), Pakistani Stock Market.

JEL Classifications: $G-11, G-15$

\section{INTRODUCTION}

Since the last three decades, the Arbitrage Pricing Model (APT) developed by Ross (1976) tends to be one of the prominent asset pricing models in the modern portfolio theory and has gained momentum in the field of financial economics respectively. The model is actually an alternative to a renowned asset pricing model named as the capital asset pricing model (CAPM) introduced by Sharpe (1964) that emphasizes on certain non-realistic assumptions that may not exist in the real world such as no taxes, no transaction costs, homogenous return expectations and emphasis on the single generating factor variable of the CAPM model termed as market portfolio to be mean variance efficient respectively. Whereas, the APT model explains that the returns' on a security are best determined by a set of economic factors based on their factor sensitivities proposing that the factor risks are of acute importance in pricing of securities.

\footnotetext{
1- Assistant Professor Faculty of Management Sciences, NUML Islamabad campus, Fmubarik@numl.edu.pk 2- Professor at Pakistan Institute of Development Economics.

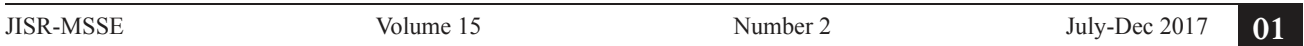


In empirical literature, two basic approaches are used to test the Arbitrage Pricing Theory (APT) (Ross, 1976) namely statistical and theoretical approaches. Statistical approaches use factor analysis to remove the common factors and then test whether the expected returns are explained by the cross-sectional fillings of asset returns on the factors. In estimating unspecified factors through factor analysis approach economic variables are used as the specified factors because measured economic factors provide additional information, thereby linking asset pricing behavior to economic conditions.

Initiated by Chen, Roll and Ross (1986), specific macroeconomic and financial market variables are supposed to capture the systematic risks of the economy. Some other factors sensitive to asset returns could be termed as small firm effect, January effect, earning-to-price ratio, book-to-market value, leverage, etc. Another prominent contribution in this regard is by Fama and French $(1992,1993,1995,1996$ and 1998, 2015) by constructing hedge portfolios by differential returns associated with firm size and book-to-market equity ratios until 1993 and recently they have extended the model by two more factors profitability and investment in 2015 respectively. This study attempts to examine macroeconomic risk factors that effect on stock returns of Pakistan and compensation paid to these returns in the form of risk premium for facing these macro risks for the time period of July 1998 to June 2014 respectively. The core objective of the study is to estimate a multifactor Arbitrage Pricing Theory (APT) model using macro-economic variables as risk factors. Further, to demonstrate the estimation efficiency, this study jointly estimates economic risk factors and risk premium associated with these risk factors. To achieve this purpose, a non-linear arbitrage pricing model is employed by following the methodology of McElroy and Burmeister, (1988).

The study contributes to the literature of asset pricing in several ways. Firstly, it identifies economic variables as risk factors that commonly affect the discount rate and the dividend stream of the stocks in the spirit of Chen et al (1986). Secondly, those macroeconomic risk factors are selected which effect the business conditions of Pakistan. Thirdly, to jointly estimate risk and risk premium by employing non-linear seemingly unrelated model. This remainder of the study is divided into four sections. Section two reviews the relevant literature in this area, section three discusses the data and methodology, section four comprises of empirical analysis and interpretation of empirical results and section five explains the summary and conclusion.

\section{LITERATURE REVIEW}

Some of the earlier studies (Gehr, 1975; Roll and Ross, 1980; Cho, 1984; Dhrymes, 1984); Shukle and Trzcinka, 1991) gave the motivation to test the Arbitrage pricing theory to determine the number of market wide factors that may influence the asset pricing models. Once tested, a need arose to determine the factors other than the market wide variables also called as the common factors that may influence the asset returns respectively. Therefore, since the development of the concept of Arbitrage Pricing Theory extensive research is being conducted to analyze the effect of macro-economic risk factors on asset returns and their contribution in compensating these risks in the form of risk premium commonly based on multi-factor models. Fama and French (2015) in their latest research have come up with the five factors identified as size, market, book-to-market, profitability and investment to estimate 
the average returns but still lack in estimating the average returns on small stocks irrespective of low profitability. On the other hand Aharoni, Grundy and Zeng (2013) find significant but weaker relationship between average return and investment respectively.

In another study, Broadie, Chernov and Johannes (2007) investigate risk premia by modeling and quantifying on factors collectively determining the returns and futures option prices. The data set comprises of S\&P 500 futures options for the time period of January 1987 to March 2003. The time series test and cross section test provide evidence of factors identified as stochastic volatility, jumps in prices and jumps in volatility in the option prices run on stochastic volatility with jumps (SVJ) and stochastic volatility contemporaneous jumps (SVCJ) model. The authors find that the risk neutral mean price jumps are regular in all models thereby providing support for volatility of price jumps and for risk premia. They conclude that the risk-neutral jump parameters differ over time; increasing during market turbulence and reducing in normalizing conditions. In another study, Iwata and Wu (2005) have investigated the asset-pricing approach in assessing the macroeconomic risk against the idiosyncratic economic shocks. The economic shocks are identified as the consumption growth, inflation and monetary policies tested against international stock market return. The dataset comprises of the quarterly observations of aggregate consumption, consumer price indices, short-term interest rates, stock market returns, foreign exchange rates and total population of Germany, Britain, Japan and the U.S. for the time period of 1973 to 1996. Based on vector auto regression (VAR) model, the authors conclude that the macroeconomic risks are observed by the international investors in the existing asset markets but are not observed in the same manner across the countries.

Guo, (2004) has examined a consumption-based model to analyze the equity premium puzzle on stocks. In the model, three market frictions are used, identified as limited stock market participation, uninsurable income risk and borrowing constraints to generate large equity premiums. In addition to the equity premiums, liquidity premiums are generated because of limited stock market participation that lowers the risk free rate for tradable assets but not the stock return. The authors conclude that the three market frictions are best risk factors to explain the cross section of stock returns of asset pricing phenomenon. Similarly, Adesi, Gagliardini and Urga (2004) have examined market coskewness in testing asset pricing models. The dataset comprises of monthly returns of 10 stock portfolios of NYSE, AMEX and NASDAQ stocks for the time period of July 1963 to December 2000 and 1-month Treasury bill rate collected from Ibbotson Associates. The authors have employed a linear two-factor model under the generalized method of moments (GMM) termed as the quadratic market model comprising of market returns and the square of market returns. The authors conclude that small firm portfolios are prone to market coskewness arisen due to negative covariance from large absolute market returns. The quadratic model is considered to be the appropriate model in testing two factors in asset pricing structure.

Koutsougeras and Papadopoulos (2004) have developed a hypothetical imperfect competitive framework in Walrasian markets. The main purpose is to provide evidence on the persistence of arbitrage with frictionless markets and imperfect competition. The structure is demonstrated through the market mechanism comprising of individuals and markets driven on strategic version of capital asset pricing model (CAPM), The authors conclude that imperfect competition may act as one of the factors in a model where arbitrage behave as persistent phenomenon 
in financial markets and no arbitrage is closely related to price taking behavior. Abadir and Talman, (2002) have employed real business cycle (RBC) model on heterogeneous productive sector based on standard monopolistic competition framework. The authors have contributed to develop an equilibrium model to work out the time series properties of GDP per capita. The model comprises of intermediate input sector, final good sector and the representative agent. Authors find long memory for the aggregate series due to temporary microeconomic shocks in the equilibrium model. The authors conclude that as the aggregate GDP possess long memory property so it could not be aligned with the individual components of GDP. The aggregation over heterogeneous units shows variability because of the increased probability of correlation of one component with different component at any later date.

Daniel, Hirshleifer and Subrahmanyam (2001) have studied a pricing model in which expected security returns are determined by risk and investor misevaluation. The models comprises of value-growth effects, fundamental/price variables and prediction future returns. The model includes two types of traders one with private information and the other with no private information. The misevaluation of returns is more vulnerable to where the judgment is ambiguous about market situation. The authors conclude that CAPM $\beta$ is a useful model for predicting future security returns no matter investors confuse the covariance matrix of returns and the usual the book/market effects are aligned with individual information content regarding security returns. Hiang (2001) has examined the relationship between real estate and corporate valuation through the application of three-factor valuation model. The dataset comprises of non-real estate sectors of hotels and industrial/commerce for the time period 1989 to 1998. The multiple index model comprises of stock market conditions, sector market conditions and property market conditions. The authors conclude that the risk premium in stocks is significant with high risk-high return market profile and that the real estate is a significant factor in corporate valuation of the firms. In another study, Ho, Perraudin and Sorensen (1996) have studied a continuous-time asset pricing model to identify risk-neural probability distributions in pricing derivatives. The data set comprises of Standard ad Poor 500 index and seven individual stocks of Citicorp, Dow Chemicals, Hershey Foods, General Motors, National Semiconductor, Pacific Gas and Electric and Kodak. Based on generalized method of moments (GMM), the authors find jump components and Brownian motions supportive of modeling asset returns.

\section{Studies on KSE}

Many studies have been conducted in Pakistan to analyze the relationship between the macroeconomic environment and the stock returns and stock market of Pakistan. Gul and Khan, (2013) have attempted to study the effect of four monthly macroeconomic factors on KSE market for the year 2000-2005 respectively. The authors find the APT model to be inaccurate for the Pakistani market to predict the stock returns respectively. Whereas, In Iqbal, Khattak, Khattak and Ullah, 2012 find the APT model to be the suitable model to predict the stock returns by employing four macroeconomic variables for the time period of 2004-2008 resptively. Line with the earlier findings, Ali, Rehman, Yilmaz, Khan and Afzal (2010) finds no causal relationship between Pakistani equity market and macro-economic indicators and also the stock exchange performance does not influence the macro-economic movement in the Pakistan. In another study, a long-run relationship between stock prices and the inflation rates, the industrial production output, the foreign exchange rates is studied by Mahmud and Dinniah (2009). 
The authors find significant results in almost all the selected Asia-Pacific countries except for Malaysia where the relationship is found weak. Javid (2008b) have further evaluated the cross section of expected returns on Fama-French three factor model and consumption capital asset pricing model and find that the consumption capital asset pricing model indicates better performance than the standard model. Hajra, Ahmed, Haq and Sadia (2007) have analyzed the relationship of the financial and the economic variables with the stock returns on the 10 industrial sectors based on the monthly data for the time period of July 1985 to July 2002. The study employs the arbitrage pricing theory model and finds that the stock returns are influenced by the financial as well as the economic indicators and creates inertia in the stock market. The relationship between the stock market returns and the financial and the economic variables tend to show the positive relationship in the daily data but insignificant in the monthly data as emphasized by Mamoon (2007) in his study by employing ARCH and vector autoregressive model with error correction. Hussain and Mahmood (2001) also find a significant cause and effect relationship between the stock returns and the macro-economic variables based on the quarterly data respectively.

This research study tries to contribute in the existing literature by employing seven macroeconomic variables with a large scale data sample for the time period of July 1998 to June 2014 respectively. Further, the economic variables have been labeled as the risk factors that commonly affect the discount rate and the dividend stream of the stocks in the spirit of Chen et al (1986) based on the joint estimation of risk and risk premium by employing non-linear seemingly unrelated model respectively.

\section{DATA AND METHODOLOGY}

This study also focuses on the risk premium earned on stock returns for facing these macro risks and the sensitivity coefficients of macro-economic risk variables identified as market return $(\mathrm{Rm})$, industrial production $(\mathrm{Q})$, call money rate $(\mathrm{CR})$, term structure of interest rate (TS), exchange rate (EX) and inflation (INF) and money supply (MS).

\section{Methodology}

To estimate the stock return by employing multiple factors is called Arbitrage Pricing Theory (APT) introduced by Ross (1976). If the factors influencing the stock returns are already known, then APT can be described by the following equation as suggested by McElroy and Burmeister (1988):

$$
\begin{aligned}
& R_{i t}-R_{f t}=\beta_{0 t}+\sum_{j=1}^{K} \beta_{j i} F_{j}+\varepsilon_{i t} \\
& R_{i t}-R_{f t}=\sum_{j=1}^{k} \beta_{i j} \lambda_{j t}+\sum_{j=1}^{k} \beta_{i j} F_{j t}+\varepsilon_{i t}
\end{aligned}
$$

Where Rit is the return on stock in the period $\mathrm{t}, \mathrm{R}_{\mathrm{ft}}$ is the return on risk free rate at the period $\mathrm{t}, \beta_{i j}$ is the sensitivity of stock $\mathrm{i}$ for factor $\mathrm{j}, \lambda_{j t}$ is the risk premium associated with pervasive influence of factor $\mathrm{j}$ on all the stocks, $F_{j t}$ is unanticipated realization of factor $\mathrm{j}$ in period $\mathrm{t}$ and is $\varepsilon_{i t}$ identified as the error term. In the study j factors include market return ( $\left.\mathrm{Rm}\right)$, inflation (INF), industrial production $(\mathrm{Q})$, money supply $(\mathrm{M})$, exchange rate $(\mathrm{E})$, call money rate (CR) and term structure of interest rate (TS). The term structure of interest rate is defined as the 
difference between the interest rate of long term government bonds and Treasury bill rate and given size of market capitalization of each stock. Among $F_{j t}, \hat{F}_{k t}$ is RMF that is estimated as the residual from the regression of Rm (KSE 100) index against all the observable factors McElory and Burmeister (1988) estimates (3.1) assuming the risk premium of factor $\mathrm{j}$ as constant, However, Merton (1973) and Cox, Ingersoll and Ross (1985) estimates the intertemporal asset pricing model (ICAPM) by relating the risk premium of factor $j$ to the volatility and a constant proportionality factor. Therefore, for time varying risk premium the study modifies the McElory and Burmeister (1988) version in line with Merton (1973) and Cox, Ingersoll and Ross (1985) framework. The risk premium can be described as:

$$
\lambda_{j t}=\alpha_{j}+P_{j} \sigma_{j t}^{2}
$$

Where $\mathrm{Pj}$ is the proportionality coefficient and $\sigma_{j t}^{2}$ is the conditional variance and factors $\mathrm{j}$ and $\alpha$ are identified as parameters. Since Merton (1973) examines the single factor model where no state dependence exists, Merton explains $\mathrm{P}$ as relative to risk aversion. If the conditional volatilities change over time then the risk premium will be time varying. Substituting (3.2) in the (3.1), rearranging and letting $c_{t}=\sum_{j=1}^{k} \beta_{i j} \alpha_{j}$ yields the following time varying APT model $R_{i t}-R_{f t}=c_{j}+\sum_{j-1}^{k} P_{j} \beta_{i j} \sigma_{j t}^{2}+\beta_{i k} P_{k} \sigma_{k t}^{2}+\varepsilon_{i t}$

Where, all the variables are the same as described above. The innovations in the economic variables are the same and are obtained as the residuals of the following equation which measures the conditional mean of $\mathrm{j}$ economic variables using the Davidian and Carroll (1988) methodology

$E\left\langle F_{j} \mid I_{t-1}\right\rangle=\alpha_{1}(L) F_{j}+\sum_{t=1}^{12} D_{t}+\varepsilon_{i t}$

Where $F_{j}$ is the kth variable, $\alpha_{1}(L)$ is the 12-th order polynomial in the lag operator $L$ and $D_{t}$ are monthly dummy variables in order to capture the seasonal variation in the mean of a variable and $\varepsilon_{o t}$ is the residual variable. The equation (3.5) is estimated in general to specific form and through stepwise backward elimination process and its insignificant components are eliminated. The variances of the $\mathrm{j}$ economic factors are

$$
\sigma^{2}\left(F_{j t}\right)=\sum_{m=1}^{12} \alpha_{m} D_{m}+\sum_{m=1}^{m} \theta_{m} \sigma^{2} F_{t-m}+w_{j t}
$$

Where $\sigma^{2}\left(F_{j t}\right)=\frac{\pi}{2} F_{j t}^{2}$ is the unconditional variance of factor $\mathrm{j}$ at time $\mathrm{t}$.

Two separate tests to determine whether or not mean monthly conditional volatilities are equal across different months are performed. For this purpose, the monthly conditional variances are regressed on 12 monthly dummies as follows:

$$
\sigma^{2}\left(\hat{F}_{j t}\right)=\sum_{m=1}^{12} \delta_{m} D_{m}+z_{j}
$$

Where, $\delta_{m}$ estimates the average conditional volatility for month $\mathrm{m}$. The F-Statistics under the null hypothesis of $\delta_{1}=\delta_{2}=\ldots \ldots+\delta_{12}=0$ indicates whether the conditional volatilities are 
on average jointly equal to zero. Another F-Statistics under the null hypothesis of $\delta_{1}=\delta_{2}=\ldots . .=\delta_{12}=0$ determine whether the conditional volatilities are on average stable from month to month. In order to avoid problem associated with two-stage estimation process, the extended APT model of each stock return represented by (3.7) is estimated jointly together with the other equations deterring all variables included using the framework of non-linear seemingly unrelated regression (NSUR). The estimation strategy involves Zelner iterative procedure. The vector $\mathrm{F}$ consists of market return (Rm), inflation (INF), industrial production $(\mathrm{Q})$, money supply $(\mathrm{M})$, exchange rate $(\mathrm{E})$, call money rate $(\mathrm{CR})$ and term structure of interest rate (TS).

\section{Data}

The data used in this study includes monthly returns for 50 stocks from July 1998 to June 2014 respectively. The economic variables included in the sample are market return $(\mathrm{Rm})$, inflation (INF), industrial production (Q), money supply (M), exchange rate (E), call money rate (CR) and term structure of interest rate (TS). The monthly data is used because the economic variables used in the study are not available on daily frequency but monthly. The stocks are selected on the basis of active trading, representative of the sector and continuous listing on Karachi stock exchange during the time period of July 1998 to June 2014 respectively. The stocks (firms) name and symbols are reported in appendix B.

\section{EMPIRICAL RESULTS}

To examine the relationship stock returns and macro-economic factors, a multifactor model is estimated. First the stationary test and descriptive statistics of data is presented.

\section{Summary Statistics of the Data}

The analysis initiates with the application of the Augmented Dickey Fuller (ADF) test to check stationarity. The industrial production, inflation, money supply exchange rate are stationary at trend and intercept at first difference log, therefore log first difference of industrial production, money supply and exchange rate is used. The call money rate and term structure are stationary at level. The results are reported in table A1 of appendix A. Similarly, the stock returns are found stationary with trend and intercept at log first difference. The log first difference results of the closing prices of the fifty stocks are reported in Table A2 of appendix A.

The descriptive statistics of the stock returns are reported in table 1. As evident from the results reported in table 1 , the stock returns are either negatively skewed or positively skewed with the values greater than 0 providing evidence of asymmetry because of the upward and downward movements of the stock returns.

Likewise, the kurtosis values of each of the 50 stock returns are lower or higher than the value 3 indicating the leptokurtic distribution with extreme values and thicker tails. Another test of normality, the Jarque-bera (JB) test is employed to test the normality of the data of the variables undertaken in the research study. If the normality of the skewness and the kurtosis is rejected then the JB statistic significantly rejects the null hypothesis that the data is normal. The results of $\mathrm{p}$ value of JB test supports the non-normality of the stock returns respectively thereby confirming for the leptokurtic distribution of the stock returns respectively.

Likewise, the skewness of call money rate, inflation and market return are negatively skewed 
and that of the rest of the variables are positively tailed indicating asymmetry of all of the economic variables. Lastly, the kurtosis values of the economic variables ranging between 1.92 to 5.66 and the significant p-values of the Jarque-Bera statistic of all of the economic variables thereby reject the hypothesis of normality of the data. The descriptive statistics of the economic variables are reported in table 2.

Table 1

Descriptive Statistics of Stock Returns

\begin{tabular}{lrrrrrrrrrrr}
\hline & Mean & SD & Skew & Kurt & $\begin{array}{c}\text { JB p } \\
\text { value }\end{array}$ & & Mean & SD & Skew & Kurt & $\begin{array}{c}\text { JB p } \\
\text { value }\end{array}$ \\
\hline ABOT & 0.00 & 0.10 & -0.53 & 4.42 & 0.00 & MARI & 0.01 & 0.13 & -0.10 & 4.07 & 0.05 \\
\hline AKBL & 0.00 & 0.15 & -1.24 & 6.47 & 0.00 & MCB & 0.02 & 0.15 & -1.00 & 5.56 & 0.00 \\
\hline AICL & 0.01 & 0.22 & -0.46 & 5.47 & 0.00 & NAFL & 0.00 & 0.07 & 0.29 & 8.21 & 0.00 \\
\hline ADOS & 0.01 & 0.12 & 0.62 & 5.37 & 0.00 & NESTLE & 0.02 & 0.11 & 0.47 & 6.09 & 0.00 \\
\hline CEPB & 0.01 & 0.11 & 0.19 & 3.73 & 0.17 & NIB & 0.00 & 0.23 & 0.50 & 3.10 & 0.07 \\
\hline CENI & 0.00 & 0.11 & -0.81 & 7.64 & 0.00 & PKGS & 0.01 & 0.11 & 0.56 & 8.28 & 0.00 \\
\hline DADX & 0.01 & 0.12 & 0.63 & 6.66 & 0.00 & PAKMI & 0.01 & 0.19 & 0.28 & 9.22 & 0.00 \\
\hline DAWH & 0.01 & 0.11 & 0.71 & 6.19 & 0.00 & PAKD & 0.01 & 0.14 & 0.38 & 3.74 & 0.05 \\
\hline DKTM & -0.01 & 0.13 & 1.81 & 13.58 & 0.00 & PGLC & 0.01 & 0.14 & 0.27 & 7.48 & 0.00 \\
\hline EFUG & 0.01 & 0.17 & -1.06 & 6.57 & 0.00 & PSMC & 0.01 & 0.15 & 0.69 & 4.89 & 0.00 \\
\hline FASM & 0.00 & 0.13 & -0.94 & 7.50 & 0.00 & PAKT & 0.01 & 0.15 & 0.43 & 5.58 & 0.00 \\
\hline FCCL & -0.01 & 0.15 & -0.70 & 4.36 & 0.00 & PIAA & 0.00 & 0.18 & 0.51 & 4.95 & 0.00 \\
\hline FABL & 0.00 & 0.14 & -1.25 & 9.38 & 0.00 & PTC & 0.00 & 0.12 & 0.02 & 3.29 & 0.80 \\
\hline FZTM & 0.03 & 0.15 & 4.30 & 30.94 & 0.00 & RCML & 0.01 & 0.13 & 0.56 & 5.10 & 0.00 \\
\hline GHNL & 0.01 & 0.21 & 0.90 & 4.28 & 0.00 & SPLC & 0.01 & 0.12 & 0.66 & 5.51 & 0.00 \\
\hline HABSM & 0.01 & 0.13 & 0.21 & 4.00 & 0.05 & SHELL & 0.01 & 0.10 & -0.16 & 3.44 & 0.46 \\
\hline HCAR & 0.00 & 0.17 & -0.60 & 5.38 & 0.00 & SITC & 0.02 & 0.10 & 0.73 & 4.31 & 0.00 \\
\hline ICI & 0.01 & 0.20 & 3.22 & 27.86 & 0.00 & UPFL & 0.01 & 0.07 & 1.19 & 12.07 & 0.00 \\
\hline ISIL & 0.01 & 0.09 & 1.61 & 10.51 & 0.00 & YOUW & 0.00 & 0.19 & 0.20 & 4.19 & 0.02 \\
\hline JDWS & 0.03 & 0.15 & 1.22 & 6.95 & 0.00 & ZAHID & 0.00 & 0.07 & 0.29 & 8.21 & 0.00 \\
\hline KASM & -0.01 & 0.17 & -0.18 & 6.86 & 0.00 & ZELP & 0.00 & 0.23 & 0.50 & 3.10 & 0.07 \\
\hline LTML & 0.01 & 0.19 & 0.65 & 5.78 & 0.00 & ZHCM & 0.01 & 0.16 & 0.26 & 5.00 & 0.00 \\
\hline LUCK & 0.02 & 0.18 & -0.27 & 4.36 & 0.00 & ZTL & -0.01 & 0.15 & -0.70 & 4.36 & 0.00 \\
\hline
\end{tabular}


Table 1

Descriptive Statistics of Stock Returns

\begin{tabular}{lrrrrrrrrrrr}
\hline & Mean & SD & Skew & $\begin{array}{r}\text { Kurt } \\
\text { JB p }\end{array}$ & & Mean & SD & Skew & Kurt & $\begin{array}{r}\text { JB p } \\
\text { value }\end{array}$ \\
\hline ABOT & 0.00 & 0.10 & -0.53 & 4.42 & 0.00 & MARI & 0.01 & 0.13 & -0.10 & 4.07 & 0.05 \\
\hline AKBL & 0.00 & 0.15 & -1.24 & 6.47 & 0.00 & MCB & 0.02 & 0.15 & -1.00 & 5.56 & 0.00 \\
\hline AICL & 0.01 & 0.22 & -0.46 & 5.47 & 0.00 & NAFL & 0.00 & 0.07 & 0.29 & 8.21 & 0.00 \\
\hline ADOS & 0.01 & 0.12 & 0.62 & 5.37 & 0.00 & NESTLE & 0.02 & 0.11 & 0.47 & 6.09 & 0.00 \\
\hline CEPB & 0.01 & 0.11 & 0.19 & 3.73 & 0.17 & NIB & 0.00 & 0.23 & 0.50 & 3.10 & 0.07 \\
\hline CENI & 0.00 & 0.11 & -0.81 & 7.64 & 0.00 & PKGS & 0.01 & 0.11 & 0.56 & 8.28 & 0.00 \\
\hline DADX & 0.01 & 0.12 & 0.63 & 6.66 & 0.00 & PAKMI & 0.01 & 0.19 & 0.28 & 9.22 & 0.00 \\
\hline DAWH & 0.01 & 0.11 & 0.71 & 6.19 & 0.00 & PAKD & 0.01 & 0.14 & 0.38 & 3.74 & 0.05 \\
\hline DKTM & -0.01 & 0.13 & 1.81 & 13.58 & 0.00 & PGLC & 0.01 & 0.14 & 0.27 & 7.48 & 0.00 \\
\hline EFUG & 0.01 & 0.17 & -1.06 & 6.57 & 0.00 & PSMC & 0.01 & 0.15 & 0.69 & 4.89 & 0.00 \\
\hline FASM & 0.00 & 0.13 & -0.94 & 7.50 & 0.00 & PAKT & 0.01 & 0.15 & 0.43 & 5.58 & 0.00 \\
\hline FCCL & -0.01 & 0.15 & -0.70 & 4.36 & 0.00 & PIAA & 0.00 & 0.18 & 0.51 & 4.95 & 0.00 \\
\hline FABL & 0.00 & 0.14 & -1.25 & 9.38 & 0.00 & PTC & 0.00 & 0.12 & 0.02 & 3.29 & 0.80 \\
\hline FZTM & 0.03 & 0.15 & 4.30 & 30.94 & 0.00 & RCML & 0.01 & 0.13 & 0.56 & 5.10 & 0.00 \\
\hline GHNL & 0.01 & 0.21 & 0.90 & 4.28 & 0.00 & SPLC & 0.01 & 0.12 & 0.66 & 5.51 & 0.00 \\
\hline HABSM & 0.01 & 0.13 & 0.21 & 4.00 & 0.05 & SHELL & 0.01 & 0.10 & -0.16 & 3.44 & 0.46 \\
\hline HCAR & 0.00 & 0.17 & -0.60 & 5.38 & 0.00 & SITC & 0.02 & 0.10 & 0.73 & 4.31 & 0.00 \\
\hline ICI & 0.01 & 0.20 & 3.22 & 27.86 & 0.00 & UPFL & 0.01 & 0.07 & 1.19 & 12.07 & 0.00 \\
\hline ISIL & 0.01 & 0.09 & 1.61 & 10.51 & 0.00 & YOUW & 0.00 & 0.19 & 0.20 & 4.19 & 0.02 \\
\hline JDWS & 0.03 & 0.15 & 1.22 & 6.95 & 0.00 & ZAHID & 0.00 & 0.07 & 0.29 & 8.21 & 0.00 \\
\hline KASM & -0.01 & 0.17 & -0.18 & 6.86 & 0.00 & ZELP & 0.00 & 0.23 & 0.50 & 3.10 & 0.07 \\
\hline KTML & 0.01 & 0.19 & 0.65 & 5.78 & 0.00 & ZHCM & 0.01 & 0.16 & 0.26 & 5.00 & 0.00 \\
\hline LUCK & 0.02 & 0.12 & 0.99 & 6.66 & 0.00 & ZIL & 0.00 & 0.13 & -0.94 & 7.50 & 0.00 \\
\hline & 0.18 & -0.27 & 4.36 & 0.00 & ZTL & -0.01 & 0.15 & -0.70 & 4.36 & 0.00
\end{tabular}

Table 2

Descriptive Statistics of Economic Variables

\begin{tabular}{lllllll}
\hline $\begin{array}{l}\text { Economic } \\
\text { Variables }\end{array}$ & Mean & $\begin{array}{l}\text { Standard } \\
\text { Deviation }\end{array}$ & Skewness & Kurtosis & Jarque-Bera & Prob. \\
\hline CR & 0.58 & 0.56 & -0.20 & 2.45 & 155.75 & 0.00 \\
\hline EX & 0.80 & 0.110 & 0.74 & 5.66 & 448 & 0.00 \\
\hline INF & 0.68 & 0.44 & -0.29 & 4.36 & 764 & 0.00 \\
\hline MS & 0.87 & 0.74 & 0.16 & 3.33 & 423 & 0.00 \\
\hline $\mathrm{Q}$ & 0.93 & 0.68 & 0.53 & 1.92 & 411.48 & 0.00 \\
\hline Rm & 0.77 & 0.44 & -0.98 & 2.93 & 419.28 & 0.00 \\
\hline & 0.29 & 0.48 & 0.22 & 1.99 & 311.58 & 0.00 \\
\hline
\end{tabular}




\section{Empirical Results of Joint Estimation of Risk and Risk Premium by APT}

The innovation of each economic variable is used as risk factor and the study estimates the sensitivities of risk factors and the premium for risk using APT. In order to estimate risk associated with economic variables, the innovation series for each variable is estimated. Following Schwert (1989), each variable is regressed on its own twelve lags and twelve monthly dummies. The backward elimination process is used and insignificant components are excluded from each equation. The residual obtained from each equation is used as innovation of the relevant variable and its absolute value is taken as a measure of Shock $(\mathrm{Fj})$ which is the risk factor associated with each economic variable. In the next step, the estimated innovations are used to estimate conditional variances by applying autoregressive process as shown in equation 3.6 for each adjusted absolute innovation series. The fitted values for each of these equations are used as conditional variance of each variable.

The estimation technique of the respective study comprises of seven equations based on the market return (RM), growth in industrial production (IP), growth in money supply (MS), inflation rate (INF), interest rate term structure (TS), exchange rate (EX), call money rate and stock return considered (Rt) and the last equation of APT to estimate the conditional mean of each economic variable respectively. In the respective study, the dependent variable is the excess monthly return of stock and the risks are the $\mathrm{Fj}$ as innovation of each economic variable. The model estimates the stock return sensitivities to risk factor called as $\beta_{j}$ and risk premium associated with risk factor $\lambda_{j}$ that tends to be time varying in nature. The 51 models are estimated based on fifty stocks and one model for the overall market. The sensitivities to risk factor and risk premium are jointly estimated; therefore each model is estimated by using Non-Linear Seeming Unrelated regression (NLSUR) technique. Table 3 reports the estimation results of the sensitivities to risk factor and the mean of the constant proportion of the factor risk premium respectively.

The findings indicate that the estimates of mean of the constant proportion of the factor risk premium seem to be significant in most of the stocks. The presence of insignificant constant proportion of the risk premium indicates that the level of risk premium can be completely explained by the APT model respectively. Further, the result of the industrial production factor show the sensitivity coefficient to be negative thereby indicating that the stock market creates inertia if a shock is observed in the real sector of the economy. On the other hand, the result of the money supply factor shows the sensitivity coefficient to be positive thereby implying that the liquidity risk makes the stock market to be more attractive. The inflation risk has positive effect on stock returns which suggests that since inflationary shock makes the financial wealth unstable so investor prefers short term investment like stock market rather than long term investment. The foreign exchange sensitivity coefficient shows the mixed effect; its exposure to the external risk gives mixed effect on stock returns. Lastly, the term structure and call money tend to show the negative sensitivity coefficients indicating that the shock in the term structure and the short term interest rate acutely affects the stock returns. The overall findings indicate that these shocks further imply that the assets other than the stocks become more risky thereby indicating a reduction in the differential risk and decrease in the risk premium associated with these stocks respectively.

1- The model is initially estimated by above mentioned lag structure and these equations are restricted by excluding statistically (insignificant) irrelevant variable using Theil specification according to which the exclusion of irrelevant variable from linea regression equation improves the efficiency of the model.

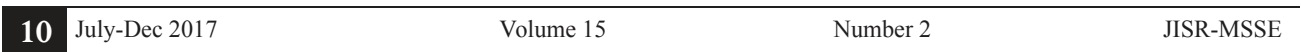


The proportionality coefficients are reported in Table 6. The coefficient Fj's in equation (3.6) represent the variation in the risk premium caused by the increase in the variance of the relevant economic risk factors. Most of the proportionality coefficients are insignificant; where significant coefficients have negative sign indicating a fall in risk premium with increase in the predictable risk. Since risk premium is reward for taking risk while holding stock market asset, if the predictable risk increases, it reduces uncertainty of the stocks. Therefore, the effect of the risk on the excess return which measures the risk premium should decline with increase in predictable risk. The insignificance of proportionality coefficient implies that that risk premium on most of the factors is constant.

Table 3

Proportionality Coefficients and Factor Sensitivities (Beta) of Individual Stocks and Overall Stocks

\begin{tabular}{|c|c|c|c|c|c|c|c|c|}
\hline Stocks & $\mathrm{C}$ & $\beta_{R M}$ & $\beta_{M S}$ & $\beta_{I N F}$ & $\beta_{I P}$ & $\beta_{C R}$ & $\beta_{T S}$ & $\beta_{E}$ \\
\hline 50 stocks & 0.03 & $0.47 *$ & $0.28 * *$ & $0.01 *$ & $-0.001 * *$ & $-0.001 * *$ & $-5.51 * *$ & $-0.39 * *$ \\
\hline t-values & 1.59 & 15.69 & 1.88 & 2.02 & -1.85 & -1.84 & -1.99 & -1.90 \\
\hline ABOT & -0.15 & $0.36 *$ & $0.28 *$ & $0.33 * *$ & $-0.002 * *$ & 0.001 & 7.80 & 0.28 \\
\hline t-values & -2.28 & 3.51 & 2.25 & 1.86 & -1.84 & 0.47 & 0.38 & 0.34 \\
\hline ACBL & -0.26 & $0.79 *$ & $1.19 * *$ & $-0.01 * *$ & $-0.001 * * *$ & $-0.001 *$ & 11.42 & -0.03 \\
\hline t-values & -3.11 & 5.88 & 1.82 & -1.98 & -1.68 & -2.01 & 0.45 & -0.03 \\
\hline AICL & 0.11 & $0.99 *$ & $2.54 * * *$ & $-0.01 * *$ & 0.00 & 0.00 & $-8.66^{*}$ & $-0.89 * *$ \\
\hline t-values & 0.86 & 4.76 & 1.74 & -1.90 & 0.19 & -0.20 & -2.22 & -1.85 \\
\hline ASKL & 0.08 & $0.12 * *$ & $2.06 * *$ & $0.003^{*}$ & $-0.003 * * *$ & $-0.001 * *$ & $-2.75 * *$ & -0.01 \\
\hline t-values & 0.88 & 1.84 & 1.80 & 2.45 & -1.79 & -1.86 & -1.99 & -0.01 \\
\hline CEPBR & -0.03 & $0.19 * *$ & 0.91 & $0.01 * * *$ & $-0.001 *$ & 0.001 & $-2.24 * *$ & $-0.85 * *$ \\
\hline t-values & -0.35 & 1.80 & 0.70 & 1.78 & -2.35 & 0.02 & -1.98 & -1.90 \\
\hline CICL & -0.03 & $0.19 *$ & 0.91 & $0.01 * * *$ & $-0.001 *$ & 0.00 & $2.24 *$ & $-0.85^{* *}$ \\
\hline t-values & -0.35 & 1.86 & 0.70 & 1.78 & -2.35 & 0.02 & 0.98 & -1.90 \\
\hline DADX & 0.15 & 0.04 & -0.20 & -0.01 & $-0.002 * *$ & $-0.01 * *$ & $-2.94 * *$ & $1.19 * *$ \\
\hline t-values & 1.96 & 0.34 & -0.15 & -1.35 & -1.89 & -1.86 & -1.85 & 1.82 \\
\hline DAWH & 0.01 & $0.58 *$ & $0.10 *$ & $0.01 * *$ & -0.001 & $-0.01 * *$ & $-3.49 * * *$ & $-0.77 * * *$ \\
\hline t-values & 0.09 & 4.60 & 2.08 & 1.83 & -0.04 & -1.89 & -1.78 & -1.78 \\
\hline$\overline{\mathrm{DKTM}}$ & -0.01 & $0.28 * *$ & 0.04 & $0.01 * * *$ & $-0.002 * *$ & $0.02 * *$ & $6.34 *$ & 0.57 \\
\hline t-values & -0.14 & 1.83 & 0.03 & 1.75 & -1.96 & 1.89 & 2.51 & 0.55 \\
\hline EFUG & 0.19 & $0.46^{*}$ & 0.74 & 0.00 & -0.003 & -0.01 & -1.50 & -1.27 \\
\hline t-values & 1.50 & 2.24 & 0.34 & 0.18 & -0.11 & -0.69 & -0.40 & -0.79 \\
\hline FEQM & 0.13 & $0.70 *$ & $1.99 * *$ & 0.001 & $-0.001 * *$ & $-0.01 * * *$ & $-2.26 * * *$ & -0.07 \\
\hline t-values & 1.25 & 4.11 & 1.90 & -0.39 & -1.81 & -1.70 & -1.71 & -0.05 \\
\hline FUJI & 0.13 & $0.47 *$ & $1.24 * *$ & $0.001 * *$ & -0.01 & 0.001 & $-3.29 * *$ & 0.06 \\
\hline t-values & 2.12 & 4.86 & 1.81 & 1.86 & -0.38 & -0.09 & -1.78 & 0.08 \\
\hline
\end{tabular}




\begin{tabular}{|c|c|c|c|c|c|c|c|c|}
\hline FABL & 0.01 & $0.86 *$ & $-1.06^{*}$ & $-0.01 * *$ & 0.002 & $0.01 * *$ & $1.63 * * *$ & $0.61 * * *$ \\
\hline t-values & 0.16 & 7.03 & -1.80 & 1.98 & 0.01 & 1.86 & 1.72 & 1.83 \\
\hline FZTM & 0.07 & $0.27 * *$ & -2.28 & $0.01 * *$ & $-0.002 * *$ & $-0.01 * *$ & $-5.07 * *$ & $-1.15^{* *}$ \\
\hline t-values & 0.58 & 1.89 & -1.13 & 1.85 & -1.78 & -1.98 & -1.88 & -1.80 \\
\hline FEROZ & 0.04 & $0.13 * *$ & $1.21 * * *$ & 0.002 & $-0.003 * * *$ & 0.001 & $-2.21 * *$ & 0.42 \\
\hline t-values & 0.39 & 1.91 & 1.77 & -0.28 & -1.77 & 0.35 & -1.80 & 0.35 \\
\hline GHNL & 0.20 & $0.62 *$ & 0.69 & $0.01 * *$ & 0.002 & -0.001 & $-5.39 * *$ & $-1.24 * *$ \\
\hline t-values & 1.43 & 2.75 & 0.28 & 1.86 & 0.13 & -0.18 & -1.85 & -1.70 \\
\hline HABM & -0.17 & $0.55^{*}$ & -0.14 & $0.01 * *$ & -0.001 & $0.01 * *$ & 1.04 & -0.16 \\
\hline t-values & -2.09 & 4.14 & -0.10 & 1.82 & -0.22 & 1.89 & 0.41 & -0.15 \\
\hline HCAR & 0.06 & $1.01 *$ & 0.29 & 0.001 & 0.002 & $-0.01 * *$ & $-7.93 *$ & 0.06 \\
\hline t-values & 0.60 & 6.07 & 0.16 & 0.40 & 0.53 & -1.82 & -2.50 & 0.04 \\
\hline ICI & 0.08 & $1.15^{*}$ & $0.66 * *$ & 0.001 & $-0.002 *$ & 0.001 & 1.15 & 2.18 \\
\hline t-values & 0.66 & 5.76 & 1.81 & 0.18 & 2.57 & 0.21 & 0.30 & 1.39 \\
\hline JDW & 0.15 & $0.69 *$ & $2.34 * *$ & $0.02 * *$ & -0.001 & 0.00 & $-3.70 *$ & $-2.37 * *$ \\
\hline t-values & 1.47 & 3.62 & 1.86 & 1.80 & -1.81 & -0.14 & -2.18 & -1.79 \\
\hline KESC & 0.05 & $0.79 *$ & $2.47 *$ & $0.02 * *$ & -0.004 & $-0.01 * *$ & $-6.46^{*}$ & -0.02 \\
\hline t-values & 0.43 & 4.64 & 2.35 & 1.81 & -1.92 & -1.96 & -1.99 & -0.02 \\
\hline KTML & -0.08 & $0.12 * *$ & $4.69 *$ & 0.003 & $-0.003 * * *$ & 0.001 & $-3.22 *$ & $-3.55^{*}$ \\
\hline t-values & -0.71 & 1.80 & 2.34 & 0.28 & -1.67 & 0.01 & -1.96 & -2.49 \\
\hline LAKS & -0.07 & $0.28 * *$ & $3.67 *$ & $0.01 * *$ & $0.003 * *$ & $-0.02 * *$ & -1.20 & $-1.01 * *$ \\
\hline t-values & -0.74 & 1.89 & 2.31 & 1.86 & 1.79 & -1.98 & -0.46 & -1.87 \\
\hline LUCK & 0.20 & $0.82 *$ & $2.27 * *$ & $0.01 * *$ & -0.001 & $-0.01 * *$ & -1.18 & 0.26 \\
\hline t-values & 2.01 & 5.14 & 1.82 & 1.98 & -0.08 & -1.85 & -0.39 & 0.21 \\
\hline MLCF & 0.37 & $2.10^{*}$ & 5.71 *** & $0.05^{*}$ & $-0.002 * * *$ & 0.01 & -2.38 & -0.49 \\
\hline t-values & 1.93 & 6.64 & 1.78 & -2.34 & -1.66 & 0.45 & -0.40 & -0.20 \\
\hline MARI & 0.07 & $0.32 * *$ & $0.24 *$ & 0.001 & $-0.004 * *$ & -0.001 & 1.40 & $-1.41 *$ \\
\hline t-values & 0.72 & 1.82 & 2.14 & 0.41 & -1.82 & -0.50 & 0.49 & -2.14 \\
\hline MCB & 0.01 & $0.93 * *$ & 1.60 & $-0.01 * * *$ & $-0.002 * *$ & $-0.01 * *$ & 1.12 & $0.72 * *$ \\
\hline t-values & 0.15 & 7.06 & 1.13 & -1.62 & 1.92 & -1.86 & 0.48 & 1.89 \\
\hline NAKIR & 0.02 & 0.07 & $1.90^{*}$ & 0.002 & -0.001 & $-0.01 * *$ & $9.50 *$ & $-0.51 * *$ \\
\hline $\mathrm{t}$-values & 0.29 & 0.70 & 2.04 & 0.28 & -0.15 & -1.89 & 0.59 & -1.77 \\
\hline NIRE & 0.21 & $0.86^{*}$ & $3.27 * *$ & 0.001 & 0.00 & 0.001 & -7.22 & -0.13 \\
\hline t-values & 1.51 & 3.79 & 1.85 & 0.09 & -1.74 & 0.29 & -1.69 & -0.07 \\
\hline PAKD & 0.31 & 0.10 & $2.84 *$ & $0.01 * *$ & $0.002 * * *$ & 0.01 & 88.84 & -0.06 \\
\hline t-values & 2.59 & 0.51 & 1.86 & 1.95 & 1.65 & 0.73 & 2.42 & -0.04 \\
\hline PAEC & -0.09 & $0.66^{*}$ & $3.68 *$ & $0.04 *$ & $-0.005 * * *$ & 0.00 & -40.57 & -2.01 \\
\hline $\mathrm{t}$-values & -0.56 & 2.45 & 1.86 & 2.17 & -1.67 & -0.14 & -0.79 & -0.94 \\
\hline PGLC & 0.14 & $0.33^{*}$ & $2.65^{* *}$ & $0.01 * *$ & 0.001 & 0.01 & 71.15 & -0.53 \\
\hline $\mathrm{t}$-values & 1.69 & 2.36 & 1.80 & 1.85 & 0.24 & 0.85 & 2.73 & -0.49 \\
\hline
\end{tabular}




\begin{tabular}{|c|c|c|c|c|c|c|c|c|}
\hline PIAA & 0.07 & $0.74 *$ & -0.30 & 0.004 & -0.003 & 0.00 & -51.01 & -0.85 \\
\hline t-values & 0.60 & 4.13 & -0.16 & 1.87 & -1.95 & 0.26 & -1.51 & -0.60 \\
\hline PKGS & -0.07 & $0.06 * *$ & $2.02 * *$ & $0.01 * *$ & $-0.002 * *$ & 0.00 & -5.84 & -1.12 \\
\hline t-values & -1.10 & 2.62 & 1.80 & 1.88 & -1.85 & 0.24 & -0.30 & -1.37 \\
\hline$\overline{\mathrm{PSMC}}$ & -0.10 & $0.50 *$ & $-2.32 * *$ & 0.00 & 0.001 & 0.00 & -37.57 & 0.27 \\
\hline t-values & -0.96 & 2.84 & -1.83 & 0.15 & 0.47 & 0.06 & -1.14 & 0.20 \\
\hline PTCLA & 0.12 & $0.74 *$ & -0.11 & $0.01 *$ & 0.002 & 0.00 & -1.13 & 0.61 \\
\hline t-values & 1.75 & 6.02 & -0.09 & 2.01 & 0.19 & -0.35 & -0.05 & 0.72 \\
\hline SAPF & 0.00 & $0.17 *$ & -0.51 & $0.02 * *$ & $-0.003 * *$ & 0.01 & 56.76 & -0.82 \\
\hline t-values & -0.02 & 2.00 & -0.30 & 1.80 & -1.84 & 0.86 & 1.98 & -0.69 \\
\hline SPLC & 0.03 & $0.34 *$ & $2.46 * *$ & $0.01 *$ & 0.002 & -0.01 & 29.91 & -1.15 \\
\hline t-values & 0.30 & 2.49 & 1.86 & 1.84 & 0.24 & -0.78 & 1.14 & -1.06 \\
\hline$\overline{\text { SHELL }}$ & -0.07 & $0.36^{*}$ & $0.75^{*}$ & $0.01 * *$ & $-0.001 * *$ & 0.01 & 19.49 & -0.48 \\
\hline t-values & -1.13 & 3.42 & 2.66 & 1.89 & 1.83 & 1.23 & 0.98 & -0.58 \\
\hline SITC & -0.01 & $0.47 *$ & 1.56 ** & 0.002 & -0.002 & 0.00 & -14.53 & -0.21 \\
\hline t-values & -0.18 & 4.41 & 1.87 & 0.40 & -1.85 & 0.54 & -0.73 & -0.26 \\
\hline UPFL & 0.06 & $0.32 *$ & $0.74 *$ & $0.001 *$ & -0.001 & -0.01 & -10.32 & -0.40 \\
\hline t-values & 1.65 & 5.77 & 1.75 & 1.96 & -1.73 & -1.58 & -0.99 & -0.93 \\
\hline YOUTM & -0.02 & 0.24 & 0.62 & $0.02 * *$ & 0.001 & 0.02 & -21.50 & -2.97 \\
\hline t-values & -0.18 & 1.05 & 0.28 & 1.83 & 0.60 & 1.22 & -0.56 & -1.86 \\
\hline ZAHID & .04 & $.23^{*}$ & $0.65^{*}$ & 0.05 & $0.007 *$ & 0.002 & $0.99 *$ & $-0.50 *$ \\
\hline t-values & 1.45 & 1.99 & 2.11 & 0.02 & 2.10 & 1.13 & 3.75 & 2.16 \\
\hline$\overline{\text { ZELP }}$ & -0.02 & 0.05 & $0.77 *$ & 0.02 & 0.01 & $0.88 *$ & 0.009 & 0.01 \\
\hline t-values & 0.21 & 1.13 & 2.15 & 1.27 & 0.58 & 1.99 & 0.02 & 1.45 \\
\hline ZHCM & 0.01 & 0.01 & $0.95^{*}$ & 0.003 & $0.09 *$ & $0.75^{*}$ & 0.02 & $0.07 * *$ \\
\hline t-values & .76 & 0.77 & 3.12 & 0.30 & 2.11 & 2.17 & 1.12 & 1.75 \\
\hline
\end{tabular}

Note: $\mathbf{C}$ stands for the proportionality coefficients and $\boldsymbol{\beta}$ stands for beta sensitivities. * shows significance level at $1 \%, * *$ shows significance level at $5 \%, * * *$ shows significance level at $\mathbf{1 0 \%}$.

\section{SUMMARY AND CONCLUSION}

This study examines the macro-economic factors as risk factors and investigates their effect on fifty stock returns listed on Karachi stock exchange; the premier stock market of Pakistan for the time period of July 1998 to June 2014 respectively. The risk factors included in the study are industrial production, call money rate, interest rate term structure, exchange rate and inflation. The study estimates jointly macro-economic risks and the premium of macro-economic risks by using non-linear seeming unrelated model. The innovation of each economic variable is used as risk factor and the study estimates the sensitivities of risk factors and the premium for risk using APT. For the estimation of the APT, the conditional mean of each economic variable the autoregressive process with monthly dummies are estimated. The residual obtained from each equation is used as innovation of the relevant variable. The results indicate that the shock of industrial production is negative showing that real sector risk 
adversely effects stock return. The risk of money supply positively affects the stock returns and the inflationary shock and exchange rate shock negatively affects stock returns. Likewise, the sensitivity coefficient of call rate and term structure is negative implying that shock in call rate and term structure adversely affects stock returns. Conclusively, the risk premium is significant for facing market risk, inflation risk and interest rate risk respectively. Also, since risk premium is reward for taking risk while holding stock market asset, if the predictable risk increases, it reduces uncertainty of the stocks. Therefore, this leads to the conclusion that the effect of the risk on the excess return which measures the risk premium should decline with increase in predictable risk. The macroeconomic risk factors are important while considering the asset pricing behavior of stock returns.

\section{REFERENCES}

Aharoni, G., Grundy, B., \& Zeng, Q. (2013Stock returns and the Miller Modigliani valuation formula: Revisiting the Fama French analysis. Journal of Financial Economics, 110(2), 347-357.

Ali,I., Rehman,K.U., Yilmaz,A.K., Khan,M.A. \& Afzal,H. (2010). Causal relationship between macro-economic indicators and stock exchange prices in Pakistan. African Journal of Business Management Vol. 4 (3), Pp. 312-319, March, 2010.

Abadir, K., \& Talmain, G. (2002). Aggregation, persistence and volatility in a macro model. The Review of Economic Studies, 69(4), 749-779.

Barone Adesi, G., Gagliardini, P., \& Urga, G. (2004). Testing asset pricing models with coskewness. Journal of Business \& Economic Statistics, 22(4), 474-485.

Broadie, M., Chernov, M., \& Johannes, M. (2007). Model specification and risk premia: Evidence from futures options. The Journal of Finance, 62(3), 1453-1490.

Burmeister, E., \& McElroy, M. B. (1988). Joint estimation of factor sensitivities and risk premia for the arbitrage pricing theory. The Journal of Finance, 43(3), 721-733.

Chen, N. F., Roll, R., \& Ross, S. A. (1986). Economic forces and the stock market. Journal of business, 383-403.

Chordia, T., \& Shivakumar, L. (2002). Momentum, business cycle, and time-varying expected returns. The Journal of Finance, 57(2), 985-1019.

Daniel, K. D., Hirshleifer, D., \& Subrahmanyam, A. (2001). Overconfidence, arbitrage, and equilibrium asset pricing. The Journal of Finance, 56(3), 921-965.

Fama, E., F., and French, K., R., (1998), 'Capital Asset Pricing Model: Theory and Practice', Journal of Economic Perspective, Vol.18(3):25-26.

Fama, E. F., \& French, K. R. (2015). A five-factor asset pricing model. Journal of Financial Economics, 116(1), 1-22.

Garcia, R., \& Luger, R. (2007). The Canadian macroeconomy and the yield curve: an equilibrium-based approach. Canadian Journal of Economics/Revue canadienne d'économique, 40(2), 561-583.

Gul, A., \& Khan, N. (2013). An application of Arbitrage Pricing Theory on KSE-100 Index; A study from Pakistan (2000-2005). Journal of Business and Management, 7(6), 78-84.

Guo, H. (2004). Limited stock market participation and asset prices in a dynamic economy. Journal of Financial and Quantitative Analysis, 39(3), 495-516.

Hiang, L. K. (2001). Real estate and corporate valuation: an asset pricing perspective. Managerial and Decision Economics, 22(7), 355-368. 
Ihsan, H., Ahmad, E., \& Sadia, H. (2007). Relationship of Economic and Financial Variables with Behavior of Stock Returns. Journal of Economic Cooperation Among Islamic Countries, 28(2).

Ho, M. S., Perraudin, W. R., \& Sørensen, B. E. (1996). A continuous-time arbitrage-pricing model with stochastic volatility and jumps. Journal of Business \& Economic Statistics, 14(1), 31-43.

Hussain F, Mahmood T (2001). The stock market and the economy of Pakistan. Pak. Dev. Rev. 40(2): 107-114.

Iqbal, N., Khattak, S. R., Khattak, M. A., \& Ullah, I. (2012). Testing the Arbitrage Pricing Theory on Karachi Stock Exchange. Interdisciplinary Journal of Contemporary Research in Business, 4(8), 839-853.

Iwata, S., \& Wu, S. (2005). What macroeconomic risks are (not) shared by international investors?. Journal of Money, Credit, and Banking, 37(6), 1121-1141.

Javid, Attiya Yasmin (2008b) Forecasting Performance of Capital Asset Pricing Models in Case of Pakistani Market. Cambridge Business Review vol.II.

Koutsougeras, L. C., \& Papadopoulos, K. G. (2004). Arbitrage and equilibrium in strategic security markets. Economic Theory, 23(3), 553-568.

Mahmud,W., \& Dinniah, N.M. (2009). Stock returns and macroeconomic variables: evidence from the six Asian-Pacific countries. International Research Journal of Finance and Economics, Issue:30.

Merton, R. C. (1980). On estimating the expected return on the market: An exploratory investigation. Journal of financial economics, 8(4), 323-361.

Peterson, S., Stapleton, R. C., \& Subrahmanyam, M. G. (2003). A multifactor spot rate model for the pricing of interest rate derivatives. Journal of Financial and Quantitative Analysis, 38(4), 847-880.

Roll, R., \& Ross, S. A. (1980). An Empirical Investigation of The Arbitrage Pricing Theory. The Journal of Finance, 35(5), 1073-1103.

Ross, S. A. (1976). The arbitrage theory of capital asset pricing. Journal of economic theory, 13(3), 341-360.

Sharpe, William F., (1964) Capital asset prices: A theory of market equilibrium under conditions of risk, Journal of Finance 19, 425-42.

\section{Appendix A}

Table A1: Unit Root Test (Economic Variables)

\begin{tabular}{lll}
\hline Economic Variables & Level & First difference \\
\hline CR & $-4.181^{*}$ & \\
\hline EX & -1.15 & $-4.16^{*}$ \\
\hline INF & -3.70 & $-5.70^{*}$ \\
\hline MS & -1.76 & $-12.60^{*}$ \\
\hline Q & -1.26 & $-7.00^{*}$ \\
\hline Rm & $-3.75^{* *}$ & \\
\hline TS & $-3.74^{*}$ & \\
\hline
\end{tabular}

Note: Unit Root test conducted on level at trend and on 1st difference at trend and Intercept. 
Table A2: Unit Root Test (Stock Returns)

\begin{tabular}{llllll}
\hline Stocks & 1st Difference & Stocks & 1st Difference & Stocks & 1st Difference \\
\hline AKBL & $-23.96^{*}$ & MLCF & $-24.85^{*}$ & DADX & $-20.73^{*}$ \\
\hline HCAR & $-21.47^{*}$ & KASM & $-21.87^{*}$ & PAKT & $-23.89^{*}$ \\
\hline ADOS & $-22.06^{*}$ & KTML & $-21.73^{*}$ & RCML & $-24.63^{*}$ \\
\hline PSMC & $-22.96^{*}$ & HABSM & $-23.37^{*}$ & DAWH & $-22.75^{*}$ \\
\hline CEPB & $-22.42^{*}$ & LINDE & $-24.44^{*}$ & SPLC & $-23.46^{*}$ \\
\hline YOUW & $-21.70^{*}$ & MCB & $-23.89^{*}$ & SHEL & $-21.72^{*}$ \\
\hline CENI & $-37.05^{*}$ & NAFL & $-22.57^{*}$ & AICL & $-21.10^{*}$ \\
\hline DKTM & $-20.65^{*}$ & JDWS & $-21.98^{*}$ & EFUG & $-22.86^{*}$ \\
\hline FABL & $-22.38^{*}$ & NESTLE & $-22.78^{*}$ & UPFL & $-23.98^{*}$ \\
\hline FASM & $-23.04^{*}$ & NIB & $-21.78^{*}$ & ZAHID & $-22.72^{*}$ \\
\hline FCCL & $-21.77^{*}$ & PAKD & $-16.80^{*}$ & ZHCM & $-23.39^{*}$ \\
\hline LUCK & $-22.56^{*}$ & PGLC & $-16.67^{*}$ & ABOT & $-22.50^{*}$ \\
\hline ZIL & $-22.34^{*}$ & PAKMI & $-23.17^{*}$ & & \\
\hline FZCM & $-25.15^{*}$ & PAKL & $-25.87^{*}$ & & \\
\hline ZELP & $-23.39^{*}$ & PIAA & $-22.79^{*}$ & & \\
\hline GHNL & $-22.31^{*}$ & PKGS & $-22.18^{*}$ & & \\
\hline SITC & $-24.72^{*}$ & MARI & $-22.68^{*}$ & & \\
\hline ISIL & $-24.59^{*}$ & ZTL & $-21.39^{*}$ & & \\
\hline ICI & $-21.16^{*}$ & PTC & $-21.66^{*}$ & & \\
\hline
\end{tabular}

Note: Unit Root test conducted on level at trend and on 1st difference at trend and intercept. (The table 2 reports the results of the stocks that have become stationary on 1st difference at trend and intercept)

\section{Appendix B}

List of the Stocks (Firms) and Symbols

\begin{tabular}{lll}
\hline S.No & Stock (firm) Name & Symbol \\
\hline 1 & Abbott Laboratories Pakistan Ltd & ABOT \\
\hline 2 & Askari Commercial Bank Ltd & AKBL \\
\hline 3 & Adamjee Insurance Co Ltd & AICL \\
\hline 5 & Ados Pakistan Ltd & ADOS \\
\hline 6 & Century Insurance Co Ltd & CENI \\
\hline 7 & Century Paper & CEPB \\
\hline 8 & Dadex Eternit Ltd & DADX \\
\hline 9 & Dawood Hercules Chemicals Ltd & DAWH \\
\hline 10 & Dewan Khalid Textile Mills Ltd & DKTM \\
\hline 11 & EFU General Insurance Co Ltd & EFUG \\
\hline 12 & Faisal Spinning & FASM \\
\hline 13 & Fauji Cement Co Ltd & FCCL \\
\hline 14 & Faysal Bank Ltd & FABL \\
\hline 15 & Fazal Cloth & FZCM \\
\hline
\end{tabular}




\begin{tabular}{lll}
\hline 17 & Honda Atlas Cars Ltd & HCAR \\
\hline 18 & ICI Pakistan Ltd & ICI \\
\hline 19 & Ismail Industry & ISIL \\
\hline 20 & JDW Sugar Mills Ltd & JDWS \\
\hline 21 & Karim Cotton & KACM \\
\hline 22 & Kohinoor TextileXD & KTML \\
\hline 23 & Linde Pakistan & LINDE \\
\hline 24 & Lucky Cement & LUCK \\
\hline 25 & MapleLeaf CementXD & MLCF \\
\hline 26 & Mari Petroleum & MARI \\
\hline 27 & MCB Bank Ltd XD & MCB \\
\hline 29 & National Fiber & NAFL \\
\hline 30 & Nestle Pak & NESTLE \\
\hline 31 & NIB Bank Limited & NIB \\
\hline 32 & Packages Ltd. & PKGS \\
\hline 33 & Pak Mod. & PAKMI \\
\hline 34 & Pak DatacomXD & PAKD \\
\hline 35 & Pak Leather & PAKL \\
\hline 36 & Pak Gum \& Chem. & PGLC \\
\hline 37 & Pak Suzuki & PSMC \\
\hline 38 & Pak TobaccoXD & PAKT \\
\hline 39 & P.I.A.C.(A) & PIAA \\
\hline 40 & P.T.C.L. & PTC \\
\hline 41 & Reliance Insurance Co Ltd & RCML \\
\hline 42 & Saudi Pak Leasing & SPLC \\
\hline 43 & Shell Pakistan & SHEL \\
\hline 44 & Sitara Chemical & SITC \\
\hline 45 & Unilever Foods & UPFL \\
\hline 46 & Yousuf Weaving & YOUW \\
\hline 47 & ZahidJee Tex. XB & ZAHID \\
\hline 48 & Zeal Pak. & ZELP \\
\hline 49 & Zahoor Cotton & ZHCM \\
\hline 50 & ZIL Limited & ZIL \\
\hline & Zephyr Textile & ZTL \\
\hline
\end{tabular}




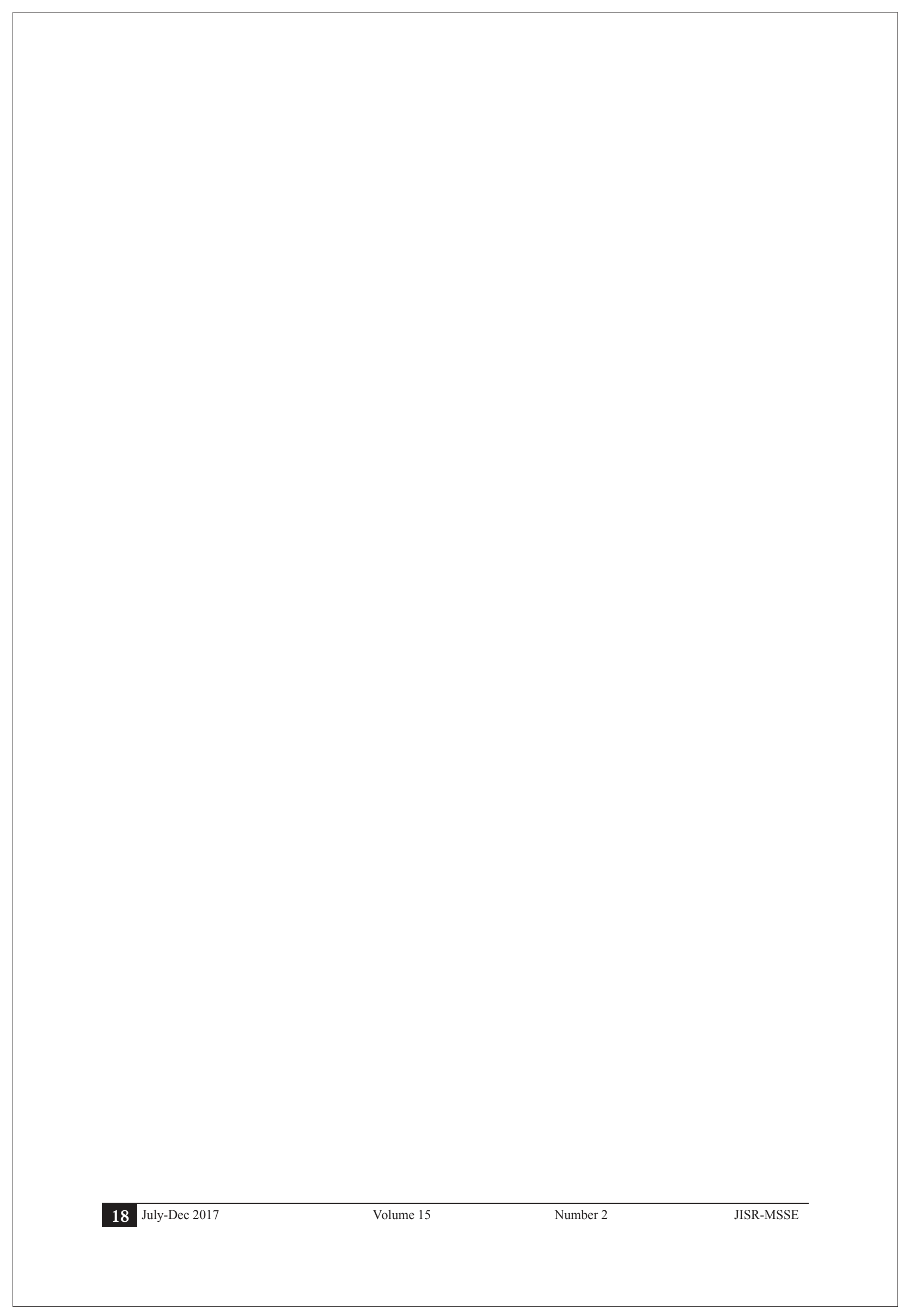

